\title{
Application of ICT in the processes of design and construction of an Orthodox Church
}

\section{Aplicación de las TICs en el proceso de diseño y construcción de una Iglesia Ortodoxa}

Luis Gimenez-Mateu (Main and Contact Author)

Universidad Politécnica de Cataluña, Departamento de Expresión Gráfica Arquitectónica, Barcelona Tech Av. Diagonal 649 2ª planta, 08028 Barcelona (Spain), +34 934016384

lluis.gimenez@upc.edu

\section{Isidro Navarro-Delgado}

Universidad Politécnica de Cataluña, Departamento de Expresión Gráfica Arquitectónica, Barcelona Tech isidro.navarro@upc.edu

\section{Galdric Santana-Roma}

Universidad Politécnica de Cataluña, Departamento de Expresión Gráfica Arquitectónica, Barcelona Tech galdric.santana@upc.edu

\section{Ernesto Redondo-Dominguez}

Universidad Politécnica de Cataluña, Departamento de Expresión Gráfica Arquitectónica, Barcelona Tech ernesto.redondo@upc.edu

Manuscript Code: 556

Date of Acceptance/Reception: 10.07.2014/04.12.2014

\section{Abstract}

This paper presents a study on the implementation of ICT (Information and Communication Technologies) in the architectural project for the new temple that the Romanian Orthodox Church builds in Barcelona (Catalonia). Initially, the reader is introduced to the special circumstances that made this project unique, given the formal complexity that had to be accommodated. In the subsequent sections, different technological tools used for the 3D representation of the building are analyzed. This is necessary for the evaluation of the project outcomes. Moreover, this approach ensured that the architectural project met the client's approval. After this, we comment on the structural peculiarities and construction limitations to which the project had to conform while retaining its maximum expression. Moreover, we reflect on the use of ICT in the process of execution of the work, allowing the reader to appreciate its quality. The objective of the article is to assess whether the procedures and devices tested in scientific research are applicable in practice, and to what extent. This analysis is performed from the point of view of the project architect, the user/customer and the contractor responsible for running the construction site.

Keywords: ICT, architecture, church, augmented reality; virtual reality.

Resumen

Este paper presenta un estudio de la implementación de las TIC (Tecnologías de la Información y Comunicación) en un proyecto arquitectónico del nuevo templo que la Iglesia Rumana Ortodoxa construye en Barcelona (Cataluña). Inicialmente, se introduce al lector a las circunstancias especiales que hicieron de este proyecto único, dada la complejidad formal que se le debe acomodar. En las secciones siguientes, se analizan diferentes herramientas tecnológicas utilizadas para la representación 3D del edificio. Esto es necesario para la evaluación de los resultados del proyecto. Por otra parte, este enfoque asegura que el proyecto arquitectónico consiga la aprobación del cliente. Después de esto, se comentan las peculiaridades estructurales y limitaciones en que el proyecto tenía que ajustarse al tiempo que conserva su máxima expresión. Por otra parte, se refleja el uso de las TIC en el proceso de ejecución del trabajo, permitiendo al lector apreciar su calidad. El objetivo de este artículo es evaluar si los procedimientos y dispositivos probados en la investigación científica son aplicables en la práctica, y en que medida. Este análisis se realiza desde el punto de vista del proyecto de arquitectura, el usuario/cliente y el contratista responsable de ejecutar la construcción.

Palabras claves: TIC, arquitectura, iglesia, realidad aumentada; realidad virtual.

\section{Introduction}

In the extant academic publications in the field of architecture and construction, it is common to find articles on cult buildings, where the authors describe their characteristics from different points of view, such as the historic, constructive, geometric, or landscape value, among many others. (Vizoso, Ferran and Bordast, 2014). For centuries, buildings of worship have been consolidated as architectural references of first order. In addition, for the purpose of better public appreciation and conservation, they are typically classified in lists or catalogs of architectural heritage by referring to organizations, such as Unesco, ICCROM, ICOMOS, Docomomo, etc., which provide patronage for the same. 
Within the field of architectural representation, there are magazines, such as the Spanish EGA, where in a sample of only last 10 issues (226 items), 46 articles (20.35\%) that based their analysis on cult buildings were identified (Calvo, Rodriguez and Natividad, 2013) (Castaño, 2013). Moreover, in the field of construction and rehabilitation, EConservation Magazine and several others specialize in the application of new technologies on the restoration and rehabilitation of heritage buildings. In these journals, many articles also make reference to structures dedicated to worship (Dietz, Catanzariti, De la Presa, Fernández \& Jimeno, 2012).

These buildings are characterized by formal complexity, and are usually geometrically and structurally superior to other more conventional structures. For this reason, they are widely used today as a basis for application of advanced analytical technologies, such as 3D laser scanner, photogrammetric restitution, videomapping (Burzon, 2013), augmented reality images or multi-spectral analysis. These technologies are ideally suited for this type of buildings, as the investigator must act in a passive mode, i.e., cannot intervene in the conception of the building, but rather analyzes the data gathered to reveal its characteristics that cannot be observed with the naked eye.

Figure 1. Screenshot of mobile display with the implementation of augmented reality in the archaeological site of Empuries, Catalonia. Virtual model applied in the right

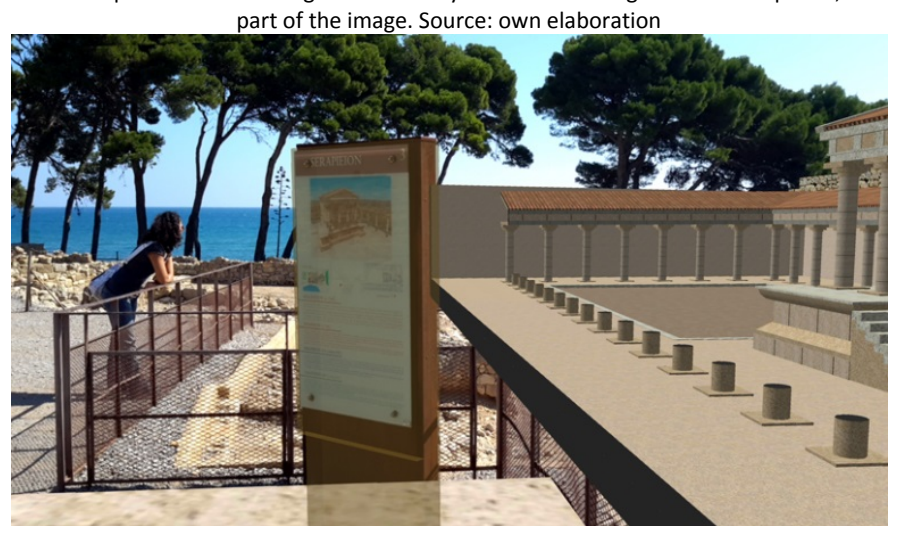

On a different subject, within the socio-economic framework subjected to the current crisis, it is rare to find a country where the activity in the construction sector has not ceased to grow. One rare example of the above is Romania, one of the countries with the lowest GDP in the European Community, but in which the Orthodox Church (majority religion, practiced by $87 \%$ of the population) has been carrying out for years a significant demonstration of economic power by building hundreds of churches across the country.

The Romanian Orthodox Church (in Romanian Biserica Ortodoxă Română - henceforth referred to as BOR) has more than 16,000 churches and places of worship scattered within or outside its territory, of which more than 2,000 have been built in the last 23 years (since the fall of the communist bloc in the late $80 \mathrm{~s}$ ). Around 500 of these buildings are subjected to annual restoration or rehabilitation initiatives. For example, the "Cathedral of the Acquittal of the People" in Bucharest is currently under construction. For this mammoth building, with a height of $125 \mathrm{~m}$, and an area of 3,000 m2, the budget for the project execution is estimated at 450 million Euros (Dunlop, 2013). Such constructive activity generates thousands of jobs and draws tens of millions of Euros a year, from economic contributions of the state, as well as voluntary payments of millions of parishioners.

This article aims to compare and contrast the work of researchers that analyze the architectural heritage (much of it based on centers of worship) with a passive attitude with regard to its implementation with the activities undertaken by the church. In particular, in Romania, thousands of buildings are being erected based on some historical principles, which seem unchanged and are still supposedly in force. The relationship between the two points allows experimenting with buildings, where the application of explorative and usually passive techniques becomes proactive because these approaches must be applied to newly erected buildings, which have for centuries been forced to preserve very specific architectural features.

The above data, without which it is not possible to understand this article, serve as a starting point for a real project under construction: the Romanian Orthodox Church in Barcelona. The intent of this article, and possibly the one that will follow, is to show how new technologies can be applied to the study of architectural landmarks. 
The current architecture of the Romanian Orthodox churches is the result of a long tradition that is a part of the ancient Byzantine models. Each architectural component is the answer to the needs of worshipers, the specific conditions and constructive techniques. Yet, it is also a reflection of the desire to stand out from other orthodox practices such as the Greek, Serbian or Russian. All these factors have led to the emergence of a unique style, which has been preserved for centuries, allowing the faithful to directly identify with the cult. The tradition and the liturgical norms of the BOR mandate that any church of new creation must meet certain standards, conditions and parameters, which are essential to performing quality ceremonies in an appropriate environment.

The rules are extensive and require a comprehensive study. However, they can be summed up in a very clear principle: any church that closely resembles another already built is of correct structure. It is also acceptable to base a new contribution on another already consolidated. This, however, leaves minimal room for maneuvering, practically prohibiting any novelty (Catedrala Mântuirii Neamului, 2010). Another important aspect is that most believers-the key users/customers-tend to a priori reject a building containing references to modern architecture. Some prominent examples of such structures are cult buildings designed by Niemeyer, Ando, Aalto, Le Corbusier and others. Worshipers believe that the orthodoxy can only be exercised in sacred spaces based on architectural canons of Christian antiquity symbolized on the inside as the universe and its different parts (Crisan, 2010).

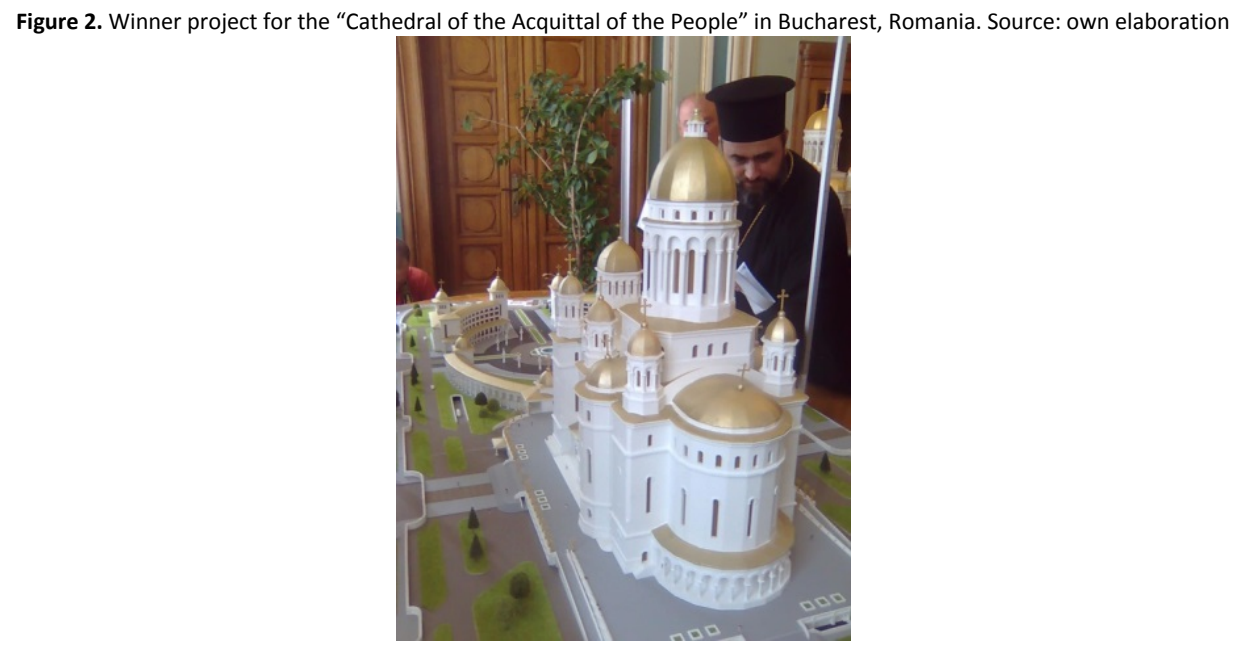

To understand the typological characteristics of the churches of Byzantine style, it is important to appreciate that their continuity in time is perpetuated by the conception of a worship space, based primarily on the symbolism and aesthetics as expressions of spirituality. This practice lasted for centuries, owing to the zeal of the masters and their dedication to their work. Yet, a few constructive systems established a modus operandi, which was largely repetitive, with few variations.

The profession was sadly marginalized when the communist regime in 1945 banned and persecuted all religious freedom. The creation of the "new man" within the socialist society implied leaving behind all traditions, and breaking links with the past. Thus, the places of worship could no longer be erected. During the next 44 years (1945-1989), the regime had not allowed the construction of any temple, and went as far as shutting down some of them. Still, it could not stifle the religious sentiment of the population, which, in the absence of civil organizations, gave the church a clear support after the fall of the regime. From the so-called "Romanian revolution", now its twenty-fifth anniversary, there was a resurgence particular of the Orthodox faith in all regions of the country. As a result of this uprising, construction of churches was again popularized, with hundreds of temples being built or rehabilitated.

\section{Bases of departure/ databases heading}

The physical orientation of the Orthodox churches is the same as that of the other Christian churches, with the main access generally by the western facade and the altar located in the lift. The primary and compulsory spatial structure is formed by a succession of chambers calls pronaos (narthex), naos (nave) and altar (sanctuary), in accordance with the theological meaning of the space and the specific form required for performing the ritual. 
The narthex is a small room, traditionally reserved for neophytes, penitents or people that are not baptized. Thus, their step to the nave, of a much larger size, produces a scenographic effect of an abrupt change of scale and perception of space, usually emphasized by the incorporation of a colonnade between the two rooms. The altar is slightly elevated and is located at the opposite end from the narthex. It is reserved for the ecclesiastic curia part, as the most sacred and inaccessible. All rooms and interior elements are covered with frescoes, created using exclusive and ancient techniques that remain unchanged in Orthodox countries. Their aim is to help the believer to enter a space of relaxation and calm, with which the liturgy should be associated.

Figure 3. Transverse cylindrical projection taken inside the naos of the Church of the Monastery of Sinaia, in the province of Prahova, Romania. Source: own elaboration

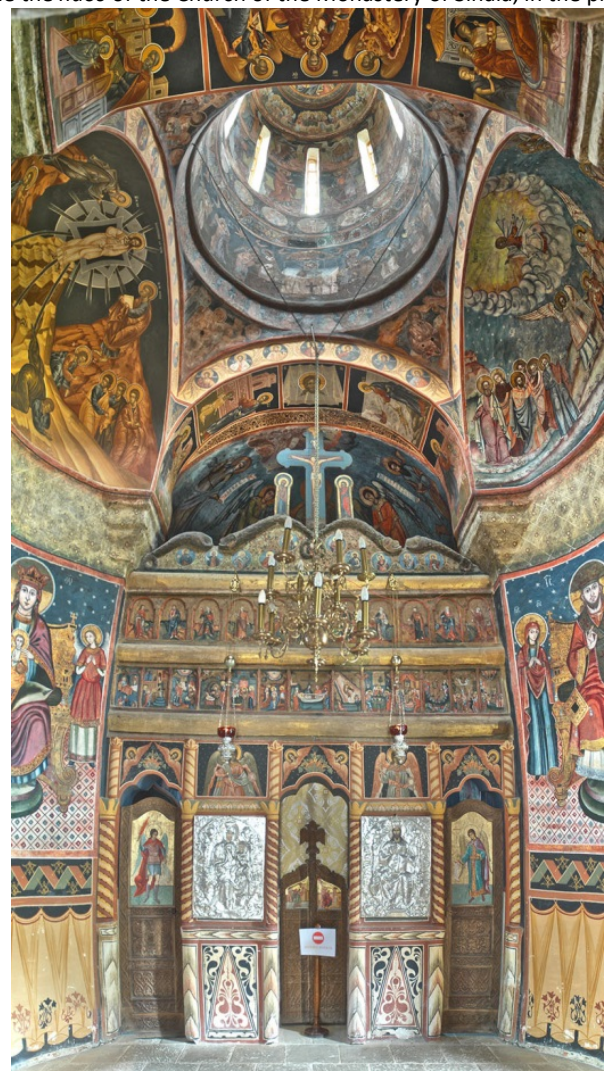

The external image of the churches is not as well defined as the marked symbology of succession of interior spaces, as it responds to the idea promoted by the orthodoxy, whereby the importance of worship lies in the interiority and recollection. The orthodox religious canons minimize the reliance on the external representativeness, appearance and opulence. Nonetheless, it is clear that, with the passage of centuries, the church has acquired an important image, where its maximum expression outside focuses on the volume of the higher dome, usually located above the nave.

Methodology

The Barcelona project has developed taking into account a commissioned complex, full of formal requirements and constructive restrictions, which are explained here, using a small sample. This type of churches is formed by the classical sequence of arches and vaults juxtaposed from the ground level up to the cross on the dome, forming each level by the transition of successive plans of square section to other of circular cross-section and vice versa. The complexity of planning such buildings lies in the symbiosis, not between form and function (given that these have been well established during centuries of evolution), but rather between form and construction. This, however, requires solutions that apply the constructive requirements to the form, while complying with regulations and laws in force, as well as meeting the requirements of the faithful.

The purpose of the present study is to explore the different processes of viewing and understanding a project based on ICT, using an example of actual construction, as well as input from some real actors (user/customer, technical professionals and contractors). These objectives require that the research is conducted in two phases: 
A) Phase 1 commences with the analysis of the communication with the user/customer during the project design process, specifying the advantages and disadvantages of the different systems considered. The findings of this step are subsequently used to define the working hypotheses, to be taken into account in the second phase.

B) Phase 2 comprises the analysis of the structure usability, as well as the results of applying ICT on a construction site. Again, input from real actors is sought, given that the structure of the church needs to meet specific guidelines.

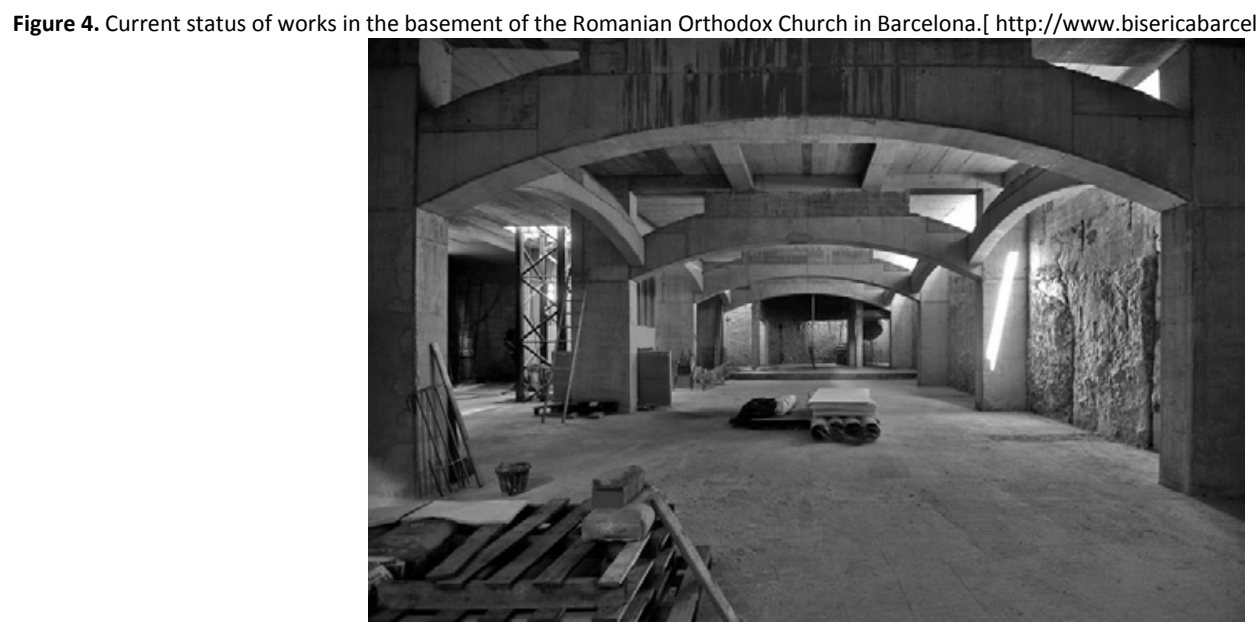

Virtual modeling

In the commissioning of the project, there is an implicit assumption that the client can follow the development of each of its phases. Given the symbolic importance of the interior spaces, the user should be given an opportunity to examine various solutions while still in the design phase. This is particularly important for arches and vaults.

In these cases, the architectural models have been traditionally used. However, this approach has limited the appreciation not only of the interior spaces, but also the real scale of the building. Thus, the use of different ICT has changed this process, as it enabled creation of 3D virtual models that allow the users to view the building from different perspectives. This approach not only reduces material costs, but also provides multiple solutions for visualization, aiding in structural understanding.

The first 3D models used in this work are generated with the software Rhinoceros v.4 and are rendered using Autodesk 3DSMax. These models correspond to the interior of the church, and are accompanied by the information yielded by previous studies in similar spaces, as well as dimensions regulated by municipal regulations. This approach allows the client to review the project and raise any concerns during the early design phases.

The first printed images created by the aforementioned approach depict the typical interior iconography of the Byzantine churches, i.e., the surfaces are not subject to any mapping, as the model only aims to differentiate their elements. To faithfully depict the interior of the church, the cameras used to create the 3D model must be positioned in a way that enables different views of the interior space.

The positioning of the cameras outside the building usually requires omitting certain surfaces in order to allow the user to see inside. This fact, in addition to not placing the viewer in a real position, underestimates the potential of the 3D model, as it needs to accommodate existing obstructions. It may also add or remove shadows in order to create the rendered images, or rely on light effects that do not reflect reality. The grand opening of the visual field is then the only way to see the inside of the model without having to locate the external point of view. In the latter case, open angles greater than 900 or 1000 are required, similar to focal lengths of 18 or $15 \mathrm{~mm}$ in full frame cameras. 


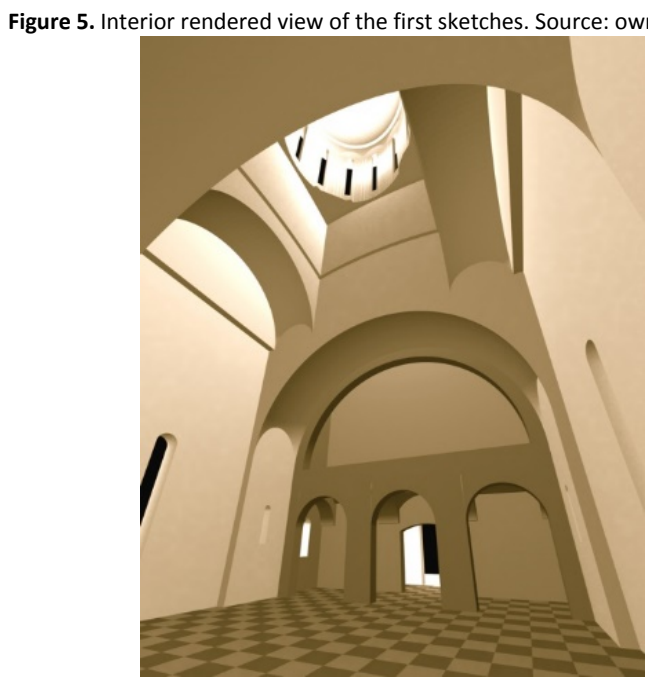

In the present case study, the angles exceeding $100^{\circ}$ are inappropriate, as the user/customer is unable to conceive the spaces, as it is difficult to reconstruct mentally the distances in the actual building and the dimensions of the different items within. Thus, the first draft of the design should aim to display the 3D model that is well understood, rather than trying to cover as wide area as possible.

When deciding on the mode of presentation of the interior spaces, it is important to appreciate that most users are not technical experts. In addition, rather than presenting a single image, an animated sequence that allows the user/client to structure mentally the succession of spaces should be used, as it aids in the understanding of the project aims.

As the user/client is not familiar with simulation in virtual environments (Fredes, Hernandez \& Diaz, 2012) and does not know how to apply various movements through a conventional keyboard and/or mouse, a technician should be on hand to provide assistance. In our study, the first draft is executed using a freely accessible software based on the interaction of various 3D models available as an Adobe pdf file, with its standard navigation tools that are available from the Adobe Reader version January 7 2005. To generate the pdf file of the 3D model, its Rhinoceros v.4 version must be converted to the MicroStation v8 2004 Edition format, which results in a significant loss of data in the shielding of the surfaces.

Figure 6. Intrados part of the Church viewed from exterior camera placement. Source: own elaboration

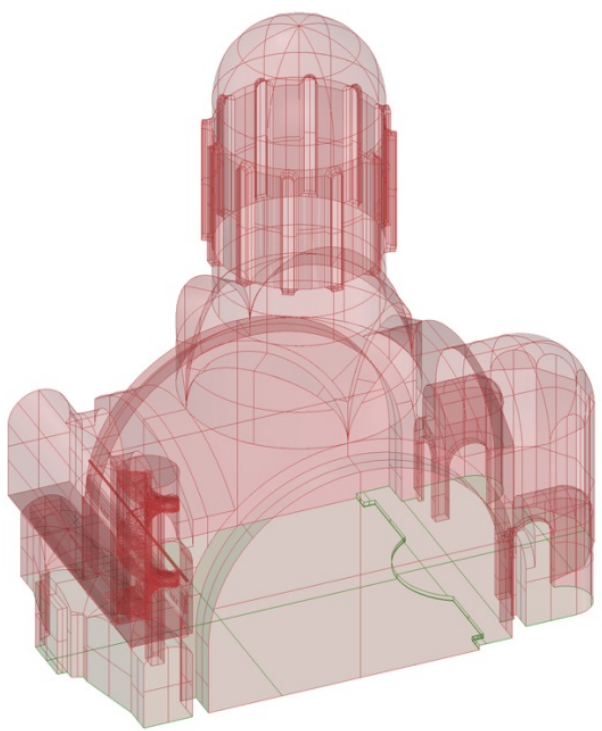


It is evident that the keyboard and mouse, interfaces common in architectural offices and academic centers, have become real barriers in the broadening of the interrelationship between 3D modelers and users. Ideally, the engineer, architect or professional should be able to interact with the computer and navigate through the virtual space with ease, while explaining the characteristics of the project. However, due to the current technical limitations, the usability of the tool is limited, hindering the user's potential for understanding the value of the project.

In addition, the customer must be able to observe both interior and exterior of the building, ideally in the actual location of the construction. As the present technology does not allow for the full sense of immersion, this study relied on Augmented Reality (AR), allowing the customer to fully appreciate the way the building will interact with its surroundings (Cirulis \& Brigmanis, 2013).

\section{Augmented reality as presentation}

The incorporation of RA is achieved by applying the plugin AR-Media v-Pro-lite, provided by Inglobe Technologies, on the program Google Sketchkup v.8 Its aim is to place a 3D model (modeling of the building exterior is conducted via Google Sketchup, now marketed by the developer Trimble) on a real-world scenario, displayed through a webcam and by means of 2D markers, based on position and orientation (Redondo, Sánchez Riera \& Fonseca, 2011), (Perey \& Terenzi, 2013).

As a part of this work, two tests were performed, both using laptop and high definition webcam. The first test involved displaying the building exterior by creating the 3D model, within a room via a flat marker of $20 \times 20 \mathrm{~cm}$ dimensions placed on horizontal surface. The second test comprised the display of the building exterior by creating the 3D model in the actual location by means of a marker of larger dimensions $(60 \times 60 \mathrm{~cm})$.

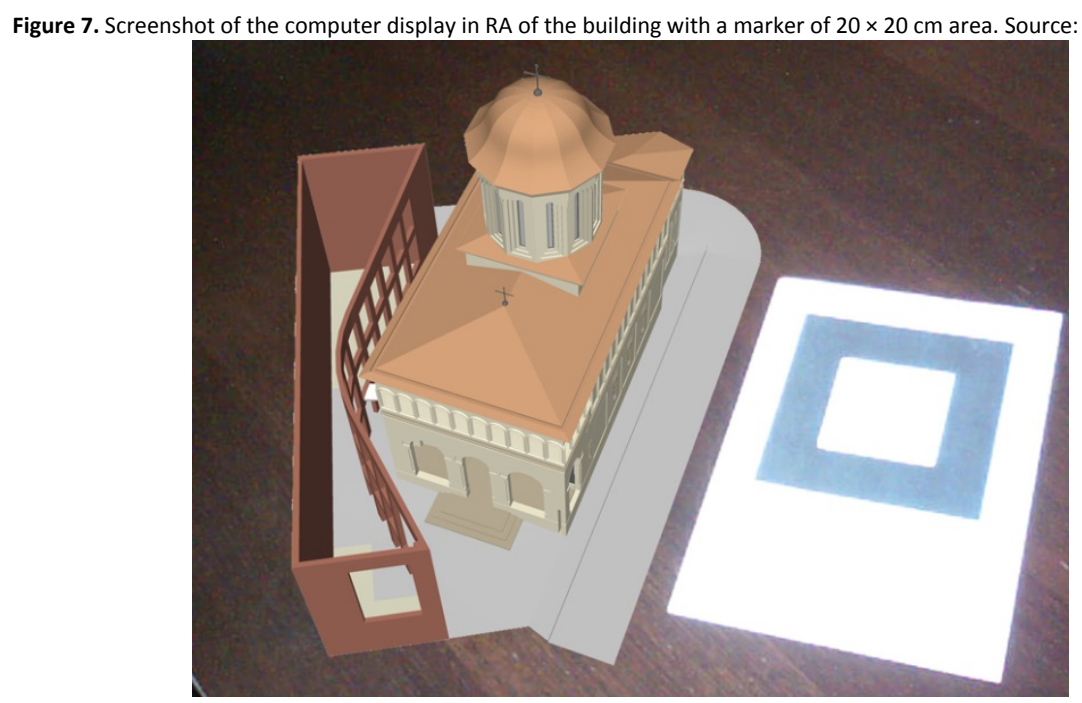

The first test yielded satisfactory results, as the PC monitor was an appropriate interface, allowing the user/customer to appreciate the 3D model in an intuitive way. Moreover, the moving and rotating the marker was easy to understand, and was characterized by acceptable coordination between the speed of movement of the marker and the response-the display of an image on the screen. The test also revealed some minor issues that needed to be addressed in order to improve the interaction. The most notable was the dim lighting in the room, causing the device to easily miss the reference of the marker and disappear on the screen. This was due to the insufficiently developed webcam stabilizers, as well as the plugin drivers. These issues needed to be resolved to avoid a continuous although tiny tremor of the image that impairs visibility of the details of the model. This problem is accentuated when the marker placed on a fixed horizontal element is controlled by the human hand.

As previously noted, the lighting direction in the 3D model does not reflect the actual lighting conditions in the room. Thus, regarding this aspect, the correspondence between the model and the physical conditions is completely absent. In addition, when the zoom or enlargement of the image is performed manually, moving the webcam to the marker causes a considerable increase in the tremor noted above. A second test was performed on the actual location of the 
project, as the aim was to provide the 3D model of the building in its actual environment. This allowed the user to assess the impact the building has on the landscape. In this respect, the viability was examined in several aspects.

First, we searched in the 3D model for the best position of the camera vector, with respect to providing an optimal perspective of the representation of the building. Second, we confirmed the suitability of that position with the help of cartographic information, with respect to being free of any obstacles. Third, we established the virtual location of the marker in the 3D program, in terms of position and orientation. Fourth, we examined the printing and location of the marker in situ and in the vertical plane. Fifth, we determined the positions using the Cartesian coordinates of the point of view in the 3D model. Sixth, we assessed the use of AR-Media plugin within Google Skecthup with webcam, in order to capture the marker and apply the 3D model on the urban environment (Rodrigues, Etchegaray, Medina \& Borda, 2012).

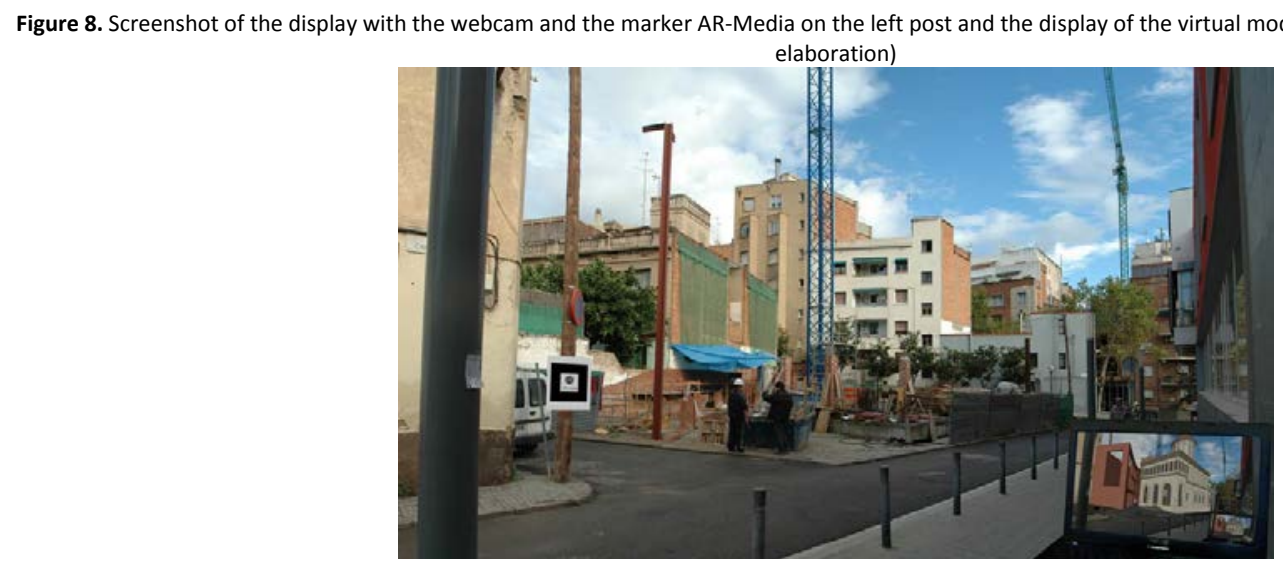

Before commencing this procedure, it should be noted that its success depends on the position and the stabilization of all the elements, from the marker to the webcam resting on a tripod or mounting brackets. When used in natural sunlight, the marker can rely on a high degree of lighting and contrast, controlling what the webcam detects and incorporating these changes into the 3D model. If the aforementioned steps are taken with a high degree of precision, the immersion of the model in the scenario is geometrically very accurate in spite of the drawbacks of the small tremor of the image and non-incorporation of shadows, in this case.

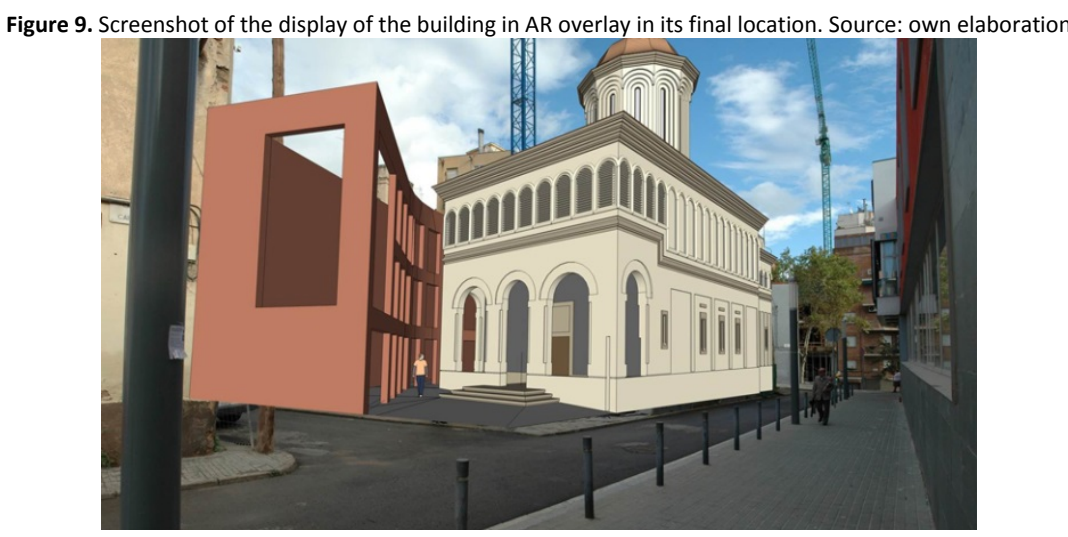

The test was performed with relative success. However, it revealed that the camera needs to be fixed and never lose contact with the marker. Moreover, it highlighted the need to remove the annoying reflections of external light that occur on the screen outdoors. Without the processes of identification by means of markers or QR codes, it is difficult to obtain a high degree of accuracy; however, the degree of user/customer satisfaction is much greater. This is due to being able to directly relate the external proportions of the building in the real physical environment with the model and assess the impact on the landscape that the structure generates, even if only from a specific point of view. 
Aiming to better understand the building design and its impact on the surroundings, we tested several new methodologies. This section refers to those that, rather than relying on static markers, employ the flat picture displayed through mobile displays, as found on the Tablet or Smartphone. Starting from the initial 3D model of the interior of the church, we decided to employ Autodesk 3dsMax to render a panoramic image of spherical $360 \times 180$ projection, as this would allow us to increase the understanding of the model (Dias, Coelho, Rodrigues, Rebelo and Cardoso, 2013). This image, despite its visualization by means of a standard monitor, allows a much more direct interaction through Tablet Samsung 10" with Android operating system.

It generates a .png file of $4096 \times 2048$ pixels of spherical type using the Mental Ray renderer for 3 dsMax, which is installed on the Tablet through files located in folders stored on the multiplatform Dropbox. For viewing, we chose the free App Store Play in Android, called TurnMe Panorama that allows viewing full screen images in $360^{\circ}$ or 2:1 ratio. The application includes the interactive choice of the opening of the visual field (zoom), so that they are resolved once the initial problems encountered in the use of 2D images are addressed. For this example, we opted for an opening of the visual field of $60^{\circ}$ in the vertical plane, with $16: 9$ screen ratio.

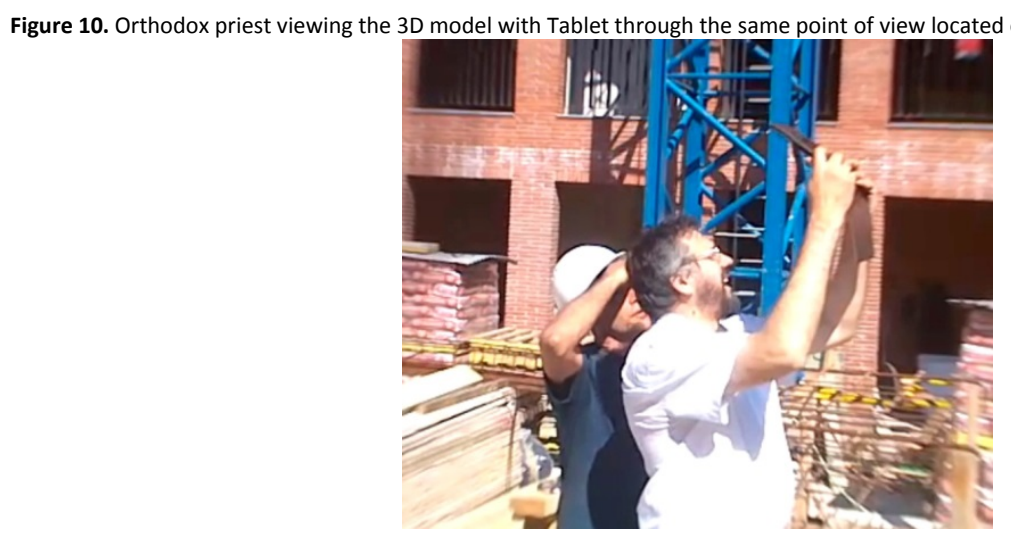

Immersion in the scene and the recognition of the modeling inside the 3D image has increased significantly due to the fact that the gyroscope of the Tablet allows the user to orient the image by offering a complete space vision (spherical) in any direction. Moreover, following the instructions is easy for the user, with the guidance of the Tablet. Thus, in this case, the App becomes a simple instrument of easy access and configuration to allow and guide the camera at will, simply by sliding one's finger on the Tablet's screen to relocate the point of view regardless of the performance of the gyroscope.

Without a doubt, the increased popularity of the Tablet and the availability of various affordable models in the market is an important aspect of the success of this initiative. In particular, the models with a display area of 10" or greater, allow the dynamic and semi-immersive 3D visualization of architectural spaces, generated from the usual CAD programs. The movement caused by the gyroscope applied to spherical images produces a feeling of control and usability not experienced in other examples tested. Its ability to be transported and maneuvered, i.e., its versatility, has made this device an inseparable companion for architecture professionals aiming to increase the clients' understanding of their projects without excessive investments in technology.

\section{Total immersion}

In view of the relative success of the previous test, this time, we decided to display the 3D model using the virtual reality glasses Oculus Development kit 2. Its features include the ability to incorporate two small screens of $960 \times 1080$ pixel resolution for each eye, full HD 1920x1080 pixel resolution for both. Moreover, owing to the gyroscope and accelerometer, the glasses respond faithfully to the movements of the user's head. For this test, we generated exports of the usual 3D model with swap file Collada, with an extension .dae suitable for interactive applications 3D. The aim was to incorporate it in the free software Unity 4.5, augmented by the Unity 3D plugin Oculus Rift, a direct application that can generate valid files for the use of the virtual reality glasses that are incorporated through an HDMI cable linking them to a computer. 
When using the glasses with a dedicated display for each eye, one can achieve the sense of three-dimensionality and the effect of stereoscopy, which creates an illusion of depth not perceived in the previous devices. Even if a static stereographic image already produces the perception, given the dimensional parallax motion, when using the glasses, the immersion in the scene is multiplied by the availability of a 3D model, where the user can see the position changes in the display, simply through the movement and orientation of his/her head. The sensations of depth and movement in an opaque type of glasses does not incorporate AR mixing with real data. In addition, the angle of vision is close to the desired 100 o, thus avoiding clipping of the image and increasing the sense of infinity.

Figure 11. Orthodox priest viewing the 3D model with Oculus virtual reality glasses linked to the computer. Source: own elaboration

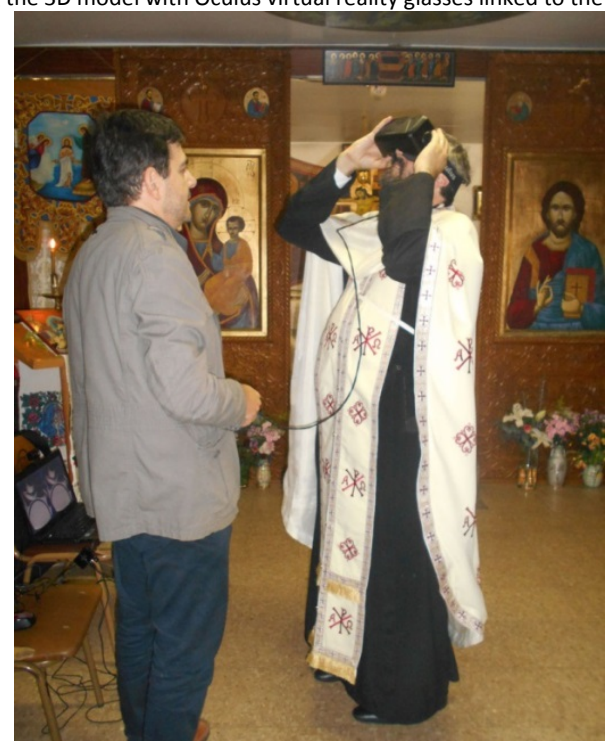

In this case, the understanding of the interior space is much greater than in any previous applications, because the information pertaining to the balance of the user's body is transmitted to the brain, along with the signals about the degrees of tilt of the head, at the same time that the gyroscope sends the same information to the software incorporated into the glasses.

The correspondence among the human movement, balance, and vision sometimes does not occur with $100 \%$ success, given that the vision responds to an image that is not real. As a result, some users experience symptoms of dizziness, sickness or imbalance. However, the utility of the glasses is undisputed as they can display not only a static image but include the possibility of displaying an animation that is controlled, i.e., generate a tour of the 3D model, allowing the user to perceive the arrangement of the space. In the present case, while this has not yet been generated, the user's understanding of the interior space has been significantly enhanced relative to the alternative tested devices.

\section{Structural solution}

Once defined and accepted, the architectural design of the individual project of the BOR in Barcelona was tested in terms of respecting and adapting to the morphology of interior surfaces, in addition to meeting all the existing structural requirements and regulations. In collaboration with BOMA (Brufau, Obiol, Moya \& Associates s.I. - now Bomalmpasa), who provided a proprietary software for linear analysis, it was possible to evaluate the reinforced concrete structure in support of the main building.

While modern buildings are erected using new materials and modern tools, the aim is to make them as visually similar to the traditional ones as possible. The main difference is that the building is no longer supported by brick walls and pillars, commonly used for centuries, but now discarded for various reasons. In this specific case, the dimensions of the BOR in Barcelona are greater than usual, and thus the CTE does not allow the brick construction in complex architectures. Thus, when determining the price per square meter of ground, the aim is to optimize the use of large load-bearing walls and buttresses. Moreover, as the technology for making bricks is not as widespread as that pertaining to the concrete, the horizontal components in the semicircular arches are better executed using concrete. Concrete is also more practical, as the speed of execution is slow when using brick, which is also more prone to damage under various conditions, such as strong winds, thermal changes or earthquakes. 
The structural calculations accommodate substantial permanent loads, using pillars, arches, beams, slabs and concrete vaults, focusing their loads on four large pillars $(40 \times 120 \mathrm{~cm})$ that constitute four great gates (shown in cyan in Figure 13) that form the central square space of the church. In these gates, there are other 4 arcs rotated by 45 degrees (shown in orange in Figure 13) and a circular ring of $30 \mathrm{~cm}$ thickness that supports the structure of the dome. That consists of 12 pillars of $30 \times 30 \times 500 \mathrm{~cm}$ until the hemispherical cupola of $30 \mathrm{~cm}$ thickness is reached (displayed in red in Figure 13). This is the classical composition of the so-called bolta moldovenească, so named because it is more common in the northern region of Moldavia (not to be confused with the country), where the squaring of the circle is performed with a double level of arches and the emergence of 8 pendentives instead of 4 .

Figure 12. 3D model of the concrete structure (without the basement) created in Rhinoceros v.4. The 7 phases of implementation correspond to the 7 different colors. (Source: own elaboration)

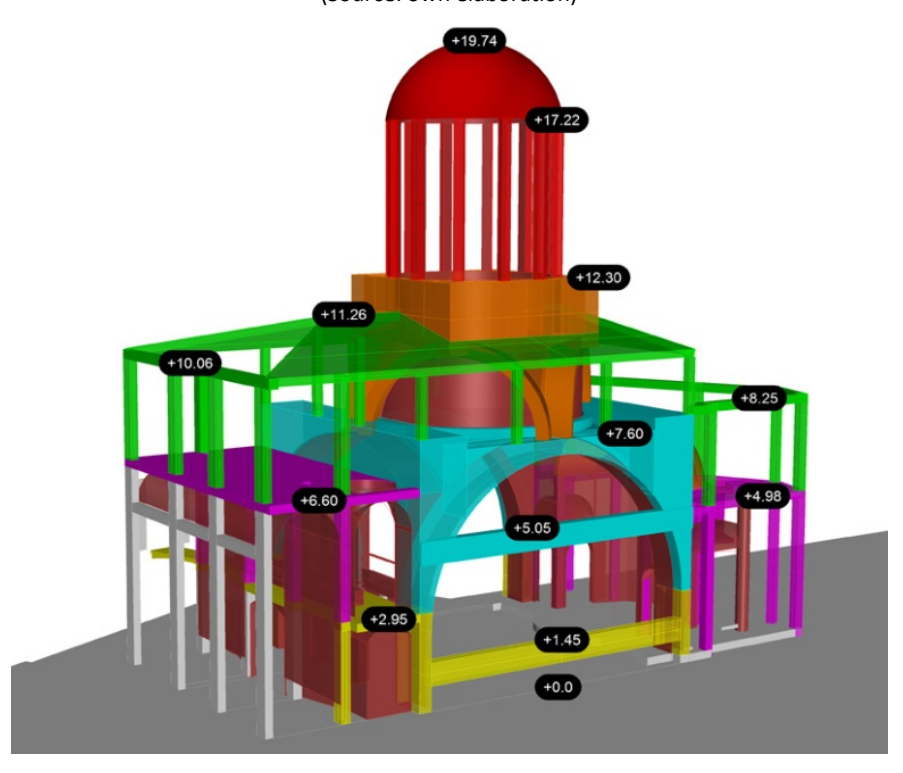

At the time of sizing the structure, the fact that it must be brick tiled both internally and externally has also been taken into account. In its interior, the porch, the narthex, the nave, the dome and the apse are covered with frescoes, which cannot be applied directly on the concrete as it has aggressive components that affect and degrade the paintings. This factor requires that the entire structure be covered with brick the thickness of which is reduced to about $4 \mathrm{~cm}$. This prevents any contact between the components of the aggressive concrete with the paint used in the future frescoes.

The pillars, arches, vaults and concrete slabs forming a fabric are invisible to the viewer, as they are the basis for the masonry that will be the intrados of the church, where the iconography will be placed. For this reason, the construction sequence must follow a predefined order, commencing with formwork scaffolding or wood or steel, followed by manual solid brick dry lining (dimensions $29 \times 14 \times 4 \mathrm{~cm}$ ) with board of hydraulic lime mortar (not cement, because it can affect the frescoes) in the ratio of 3:1, armed with steel arches, pillars and straps, and concrete pouring HAS-25/B/20/Ila. In this way, the brick is positioned directly on the concrete, creating a barrier and protecting the frescoes. The concavity of arches and vaults allows perfect adhesion of the coated brick.

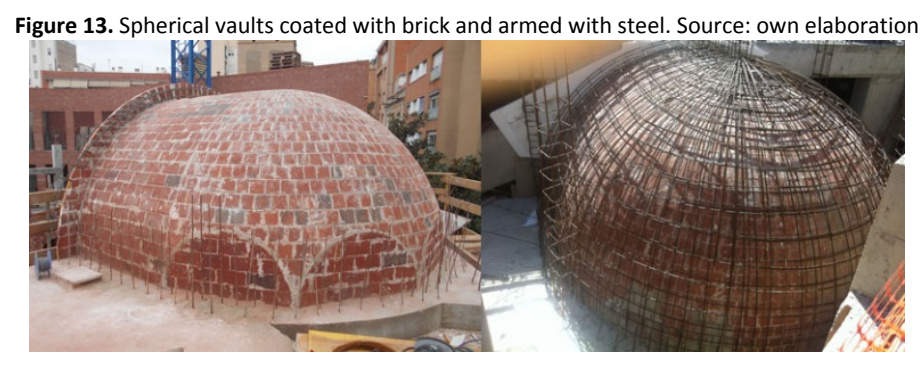

This technology has been widely used in the construction of recently erected temples in Romania, where it has also replaced the classic structure of brick mixed carrier with the concrete and brick lining. While this provides greater security to the development of the work, it requires more complex design and calculation processes. 
Given the many problems associated with the understanding of the geometry of the structure, which affects its actual design and construction (verified during the partial implementation of the basement), the next step is to introduce the RA into the construction process and examine the interaction among the various classes of professionals. In this particular case, it was absolutely necessary to ensure fluid dialog between the Project Manager and the remaining contributors, which is commonly fraught with difficulties because of the poor geometric and spatial understanding the operators typically have. This is particularly problematic in works such as the one described above, as they are unique and cannot benefit from information on any type of conventional construction.

Thus, to overcome this issue, we take advantage of the 3D model adopted by the user/customer to input thee data pertaining to the geometry of the structure, calculated by BOMA. The formal complexity of the set also lies in its geometric characteristics, as the structural model is presented in $5 \mathrm{~cm}(4 \mathrm{~cm}+1 \mathrm{~cm}$ of brick board) relative to the finished model. This introduces significant differences between the 3D model for the structure and the one used to the finish surface. In this phase of the project, we rely on the Rhinoceros panoramic images of spherical projection $(360 \times 180)$, or on the structure to be viewed by the site manager directly on the site. As above, Tablet Samsung $10 "$ with Android operating system and app TurnMe Panorama is used in.

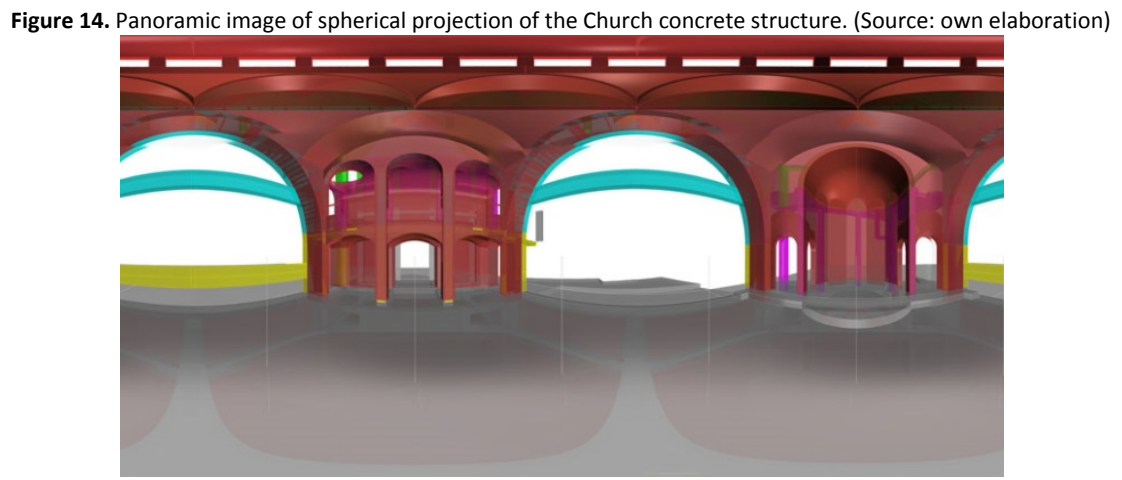

When tested directly at the construction site, the stability of the image is much higher than with the plugin Ar-Media. Moreover, its degree of usability increases because the app allows avoiding the use of Tablet, since it is also compatible with Smartphones with Android or Windows phone operating systems. Using multiplatform Dropbox, the necessary file folders are shared, allowing the site manager to view the panoramic image files in the jpg format. This aspect greatly facilitates the work on the site and increases the formal understanding of the available virtual images of the structure. The gyroscope allows the user to view the full screen display and rotate the images by $360^{\circ}$ to increase the understanding.

In this case, the display of the panoramic view depicts a specific point of view determined by the $x, y, z$ coordinates in the virtual model, which can be easily found by the surveyor (or the same site manager), as these are referenced to the point of absolute origin. If the two points (i.e., their $x, y, z$ coordinates) match, any user/operator can view the surrounding space and better understand the next step to perform. In the case of the application TurnMe Panorama, or other similar software, such as the so-called Photosphere HD Live Wallpaper, visual referencing between an image and reality must be conducted with the aid of the displacement of the image on the screen with one's finger. In positions for which reference elements are absent, the panoramic images or discrete marks that symbolize the virtual position of the 4 cardinal points are required. Alternatively, the user can rotate the mobile phone in order to be able to approximate the orientation of the same with respect to the geographical north.

Figure 15. Operators viewing in Tablet panoramic image of the structure. Source: own elaboration

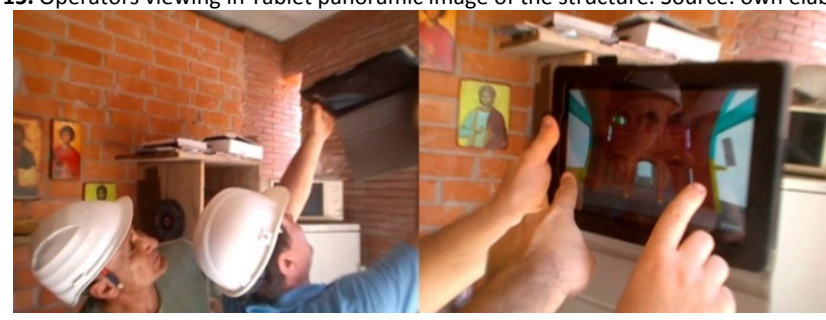


For accurate georeferencing of the image displayed on the specific point, the mobile device not only must be placed in the same relative coordinate, but its orientation should be optimal. To go a step further, it was decided to use the Krpano 1.17 Multiresolution provided by Krpano Gesellschaft mbH plugin for html5. The same panoramic images (in jpg file format and $360 \times 180$ pixel size are this time introduced in the script of the plugin that generates a file in html5 web language. Its advantage is that it is accessible via any standard internet browser, either using a PC, or a mobile device, such as Tablet or Smartphone.

This time, the display is not linked to the downloading and installing an app on the device, as it only requires opening the browser and requesting the generated web page. The image is displayed at full size on the screen, if this has been scheduled. After various tests that verify that the opened html file shows the image in optimal resolution and enables the zoom function, some errors in the use of the gyroscope on the part of the Android systems 4.0 or higher were identified, as it is unable to control the movements properly.

However, the same file system works perfectly under the Apple IOS, where the drivers of the gyroscope adequately respond to the movements of the device on the screen, showing the good orientation of the image. In addition, if in the IOS devices with Apple system the usual geolocation by GPS is activated, the image on the screen is auto oriented in reference to the geographical north, by accurately matching it with the mark on the image. In the case discussed here, while the geolocation by the compass of the device is correct, it is still not suitable for modifying the actual design.

\section{Conclusions}

The high degree of spatial perception is achieved with the incorporation of the RA techniques that combine the virtual elements on a real-world scenario perceived via Tablet. When either 2D spherical image or 3D models are referenced, the sensory data produced by the movement of the arms and body of the user/client can perfectly relate the image being viewed on the screen with the position in real space, recognizing the volumes with a greater degree of accuracy.

It is thus envisaged that, in the not too distant future, when more accurate devices in combination with AR are available, use of ICT will allow a high degree of usability of this approach. Regarding a greater immersion in virtual scenarios, future version of glasses supporting RA that incorporate Meta Spaceglasses are expected to yield better results. The increased precision will also be achieved via the use of georeferencing, if the Global Navigation Satellite System Galileo (GNSS) is available in Smartphones or Tablets.

Work funded by the teaching innovation project "EDU2012-37247/EDUC: E-learning 3.0 in teaching Architecture. Case studies of educational research for the immediate future" of the Government of Spain. 
Burzon, A. (2013). Mapping Sant Climent de Taüll. November 24, 2014, of burzoncomenge. Retrieved from: http://www.burzoncomenge.com/ca/treballs/videomapping-1123-sant-climent-de-taull

Calvo López, J., Alonso Rodríguez, M. Á., \& Natividad Vivó, P. (2013). La bóveda de la capilla de la Virgen del Alcázar en San Patricio de Lorca. Experimentación geométrica en la arquitectura renacentista del sur de España. Revista EGA Expresión Gráfica Arquitectónica, 18(22), 122131.

Castaño Perea, E. (2013). Trazas renacentistas en dos cúpulas de Vandelvira: teoría y praxis. EGA. Revista de expresión gráfica arquitectónica, $18(21), 140-149$.

Cirulis, A., \& Brigmanis, K. B. (2013). 3D outdoor augmented reality for architecture and urban planning. In Procedia Computer Science, 25 , 71-79.

Crisan, M. (2010). Restaurarea structurala a claridilor de cult ortodox din Tara Romaneasca si Moldova. Bucharest: Editura Universitara lon Mincu.

Catedrala Mântuirii Neamului (2014), website Retrieved 24.nov.2014 from: http://www.catedralaneamului.ro/index.php/simbolism-teologic

Dias, L., Coelho, A., Rodrigues, C., Rebelo, A., and Cardoso, A. (2013). GIS2R - Augmented Reality and 360 Panoramas Framework for Geomarketing. CISTI, Lisboa, 2013, 1-5.

Dietz, C., Catanzariti, G., De la Presa, P., Fernández, V.M. \& Jimeno, A. (2012). 3D Documentation using terrestrial Laser Scanning of the Remanis of the Jesuit Mission in the Region of Lake Tana, Ethiopia. E-Conservation Magazine, 24, 106-125.

Dunlop, T. (2013). Romania's costly passion for building churches. November 24, 2014, London: British Broadcasting Corporation. Retrieved from: http://www.bbc.co.uk/news/magazine-23420668

Fredes, Claudio A, Hernández, Juan P \& Díaz, Daniel A. (2012). Potencial y Problemas de la Simulación en Ambientes Virtuales para el Aprendizaje. Formación universitaria, 5(1), 45-56. ISSN 0718-5006

Perey, C. \& Terenzi, G. (2013). AR-Assisted 3D Visualization for Urban Professional Users. ARmedia First White Paper of Inglobe Technologies.

Redondo, E., Sánchez Riera, A. \& Fonseca, D. (2011). Visual interfaces and user experience: augmented reality for architectural education: one study case and work in progress. Communications in Computer and Information Science. Springer Verlag, 166, 355-367.

Rodrigues, F., Etchegaray, F., Medina, H. \& Borda, A. (2012). Desenvolvimento de Aplicativo para Visualização de Patrimônio Histórico-Arquitetônico em Realidade Aumentada. In Proceedings of the 16th Iberoamerican Congress of Digital Graphics Graphics. Fortaleza, Brasil.

Vizoso, Ferrán, \& Bordas, Núria. (2014). Restauración Iglesia St. Pere, Corbera D'Ebre, España: Ferrán Vizoso, Núria Bordas, 1999 - 2013. ARQ (Santiago), 87, 54-57. ISSN 0717-6996 